\title{
Design analysis of ORC micro-turbines making use of thermal energy of oceans
}

\author{
Marian Piwowarski, Ph.D. \\ Gdansk University of Technology, Poland
}

\section{ABSTRACT}

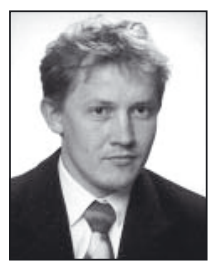

The article presents the results of the analysis of energy conversion cycles making use of thermal energy of oceans. The objects of analysis were two cases of closed Organic Rankine Cycle (ORC) power plants, which were: the cycle in which the vapour of the working medium was produced by warm oceanic water in the circum-equatorial zone, and the so-called "arctic" cycle in which this vapour was produced by non-frozen water in the circumpolar zone. Between ten and twenty low-boiling media were examined for which operating parameters were optimised to obtain the highest cycle efficiency. A preliminary design of an ORC turbine which was obtained by optimising basic design parameters is included. It has been proved that realisation of the Ocean Thermal Energy Conversion (OTEC) cycle is possible both in the warm and permanently frozen regions. The results of the calculations have also revealed that the efficiency of the OTEC cycle is higher in the circumpolar zone. Selecting a low-boiling medium and designing a highly efficient turbine operating in both abovementioned regimes is technically realisable.

Key words: Ocean Thermal Energy Conversion (OTEC) cycles; Organic Rankine Cycle (ORC); low-boiling media; steam turbines; turbine design

\section{INTRODUCTION}

Seas and oceans are the world largest reservoirs in which thermal energy of sunbeams is accumulated. The sunlight falling on the ocean surface is intensively absorbed by the water which collects all its energy in the shallow surface layer. Unlike the solar energy, the intensity and concentration of which is subject to steady cycles and accidental disturbances, the energy of seas and oceans reveals stable intensity, both in $24 \mathrm{hr}$ and annual time scale. This is an important advantage as it leaves aside the problem of energy storage and its costs. In tropical regions of oceans, approximately between $15^{\circ}$ north and $15^{\circ}$ south latitude, the heat collected from sunbeams heats the water in the shallow surface layer to the practically constant temperature nearing $28{ }^{\circ} \mathrm{C}$. The annual average temperature in the entire region ranges approximately between $27^{\circ} \mathrm{C}$ and $29^{\circ} \mathrm{C}$. Below the warm surface layer the water becomes colder, and at the depth between 800 and $1000 \mathrm{~m}$ the water temperature drops down to about $4{ }^{\circ} \mathrm{C}$. Depending on the region, temperature changes can take different courses and for instance, at the depth of $200 \mathrm{~m}$ the water temperature can be already as low as $7{ }^{\circ} \mathrm{C}$. The temperature difference is kept constant all year round, with small deviations of a few Celsius degrees resulting from seasonal weather and day/night changes. Utilisation of this difference bases on the application of a working medium which evaporates at the surface temperature and condensates when cooled by the water taken from the much deeper level. This type of energy conversion is frequently referred to as
Ocean Thermal Energy Conversion (OTEC). A key issue in case of localisation of a number of OTEC units close to each other is the distance between them. Due to outlet water disposal, this distance should not be excessively small. This aspect is of high importance as the surface waters are cooled each time the outlet water is disposed from an open OTEC installation. In the system of combined units the excessive amount of water disposed by the system can considerably decrease the temperature of the surrounding regions, which in turn can affect the efficiency of all power plants situated nearby. Initial concepts on how to make use of the energy collected in seas were presented by J. d'Arsonval (France) in 1881. The first experimental object of this type was built by his pupil, G. Claude, in Matanzas near Cuba in 1928. The power output of the installation was $22 \mathrm{~kW}$ and it worked only for 2 weeks, after which was partially destroyed by typhoons. In late fifties of the last century French researchers began again to study the subject, building an installation in the Ivory Coast region. Further development in this field was initiated in 1960 by Andersens, two Americans, father and son, who established a private company exploring thermal energy from seas using OTEC technology. A few years later a $50 \mathrm{~kW}$ semi-technical system was built in the USA, which was followed by a fully technical one of $1 \mathrm{MW}$ power output, built in 1980 and installed on a reconstructed ship. Cold water amounting to 450 tonnes was delivered using polyethylene pipes having the diameter of $1.5 \mathrm{~m}$ and length of $700 \mathrm{~m}$. In 1981, on Nauru island in Japan a stationary $100 \mathrm{~kW}$ installation was built, to which $1410 \mathrm{t} / \mathrm{h}$ 
Tab. 1. List of demonstrative OTEC power plants [8]

\begin{tabular}{|c|c|c|c|c|c|}
\hline Item & Year & Location & Producer & Power $[\mathbf{k W}]$ & Cycle \\
\hline 1 & 1930 & Cuba & Claude, France & 22 & Open \\
\hline 2 & 1979 & Hawaii & Mini OTEC, USA & 53 & Closed \\
\hline 3 & 1980 & Hawaii & OTEC-1, USA & 1000 & Closed \\
\hline 4 & 1982 & Nauru & Toshiba\&TEPC, Japan & 120 & Closed \\
\hline 5 & 1984 & Saga & Saga University, Japan & 75 & Open \\
\hline 6 & 1992 & Hawaii & Nelha, USA & 210 & Closed \\
\hline 7 & $1992-1998$ & Hawaii & Nelha, USA & 50 & Closed \\
\hline 8 & 1995 & Saga & Saga University, Japan & 9 & Closed \\
\hline 9 & 2000 & Tuticorin & NIOT, Indie & 1000 & Closed \\
\hline
\end{tabular}

of cold water having the temperature of $8^{\circ} \mathrm{C}$ was delivered from the sea bottom using a $1093 \mathrm{~m}$ long pipe. In this area the temperature of surface waters nears $30^{\circ} \mathrm{C}$. About $75 \%$ of the produced energy was used for own purposes of the installation and the remaining part was transmitted to the electric network. Tab. 1 collects demonstrative OTEC power plants which were the objects of examination.

Plans are to build a power plant fed by the Gulf Stream which flows near the USA. The temperature difference between the Gulf Stream and the surrounding waters secures efficient recovery of thermal energy at remarkable cost reduction resulting from a short distance between the lower and upper heat sources, and the disposal of the used water to the Gulf Stream which will transport it away. At the beginning of the 21-th century, numerous countries, mainly Australia, Germany, France, the United Kingdom, the Netherlands, Italy, India, Japan, Canada, and the USA, began to value thermal energy collected from the oceans to produce electric energy and intensified their activities oriented on development of technologies leading to most effective use of this energy $[2 \div 7,9,13,15,18,20 \div 22]$. Technical solutions of these installations base on the Open Cycle - Ocean Thermal Energy Conversion (OC - OTEC) cycle and the Closed Cycle - Ocean Thermal Energy Conversion (CC - OTEC) cycle. Open systems make use of the water pumped directly from the ocean. The water evaporates when flowing through the low-pressure chamber in which the pressure is decreased below the condensation point. This way salt is separated from the water. Thermal energy needed for steam production in the evaporator is released by the surface water which is the upper heat source. After leaving the evaporator, the produced steam expands in the turbine and then flows to the condenser cooled with the water taken from deeper levels of the ocean. Oxygen, carbon dioxide, and nitrogen, which have been dissolved in the oceanic water and are not subject to condensation in the condenser, are released to the environment using the vacuum pump which increases the pressure to the level required for purifying the installation from these gases (Fig. 1). A characteristic feature of open installations is relatively high speed of medium evaporation, which is directly related with the processes of mass and heat transfer. The steam produced in the heat exchanger reveals low, or zero salt concentration, along with relatively low toxicity. Further possible utilisation of the medium used in the system can be an additional attractive feature of the discussed cycle in places where clean water is hardly accessible and highly required.

In case of closed systems, the principle of their operation is the same as in the Rankine cycle (Fig. 2). In this concept the surface water is also used as the upper heat source. The energy from outside is passed to the medium in the heat exchanger to make it evaporate. Due to smaller specific volume of the working medium, the dimensions of the devices are smaller than in open cycle installations. Proposals can be found in the literature to combine OTEC systems with solar collectors, thus creating so called Solar and Ocean Thermal Energy Conversion (SOTEC) systems. Such solutions increase the efficiency of the entire cycle [6], [22].

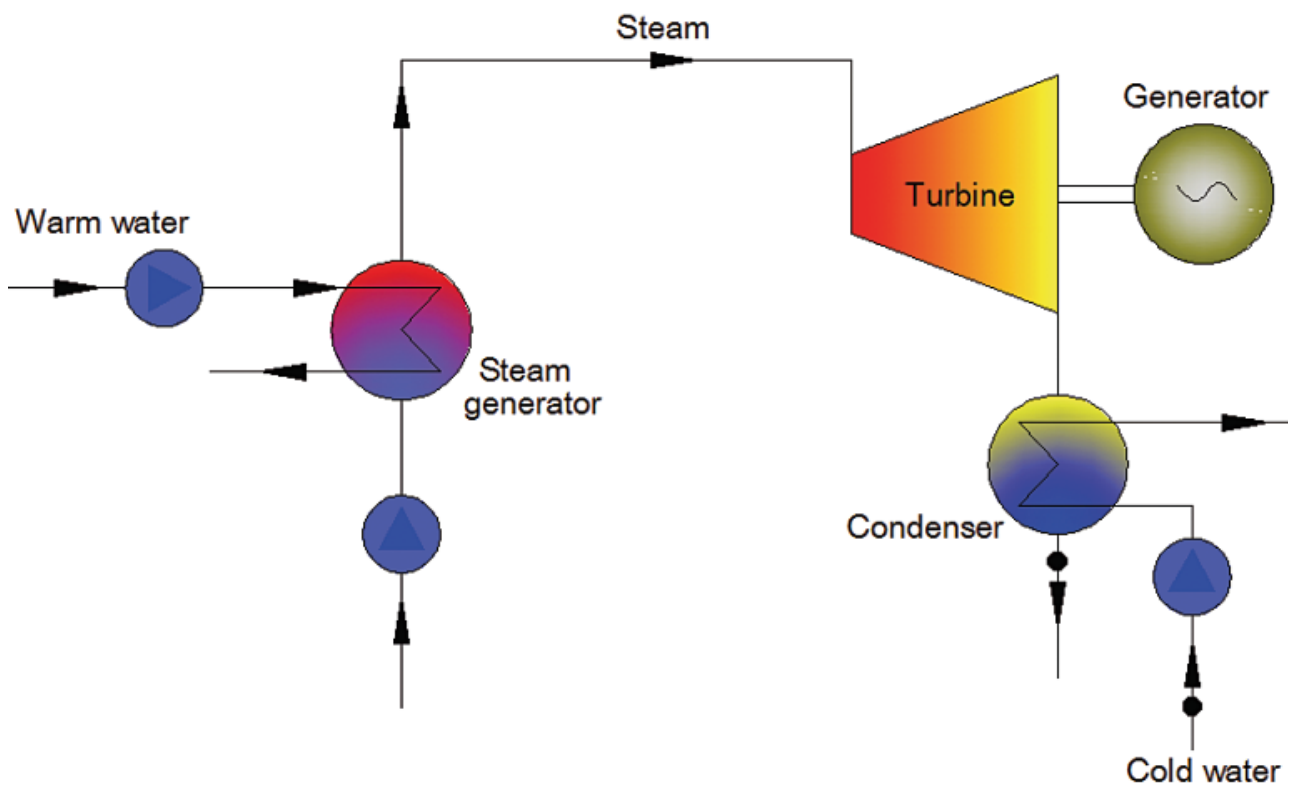

Fig. 1. Scheme of open OTEC cycle 


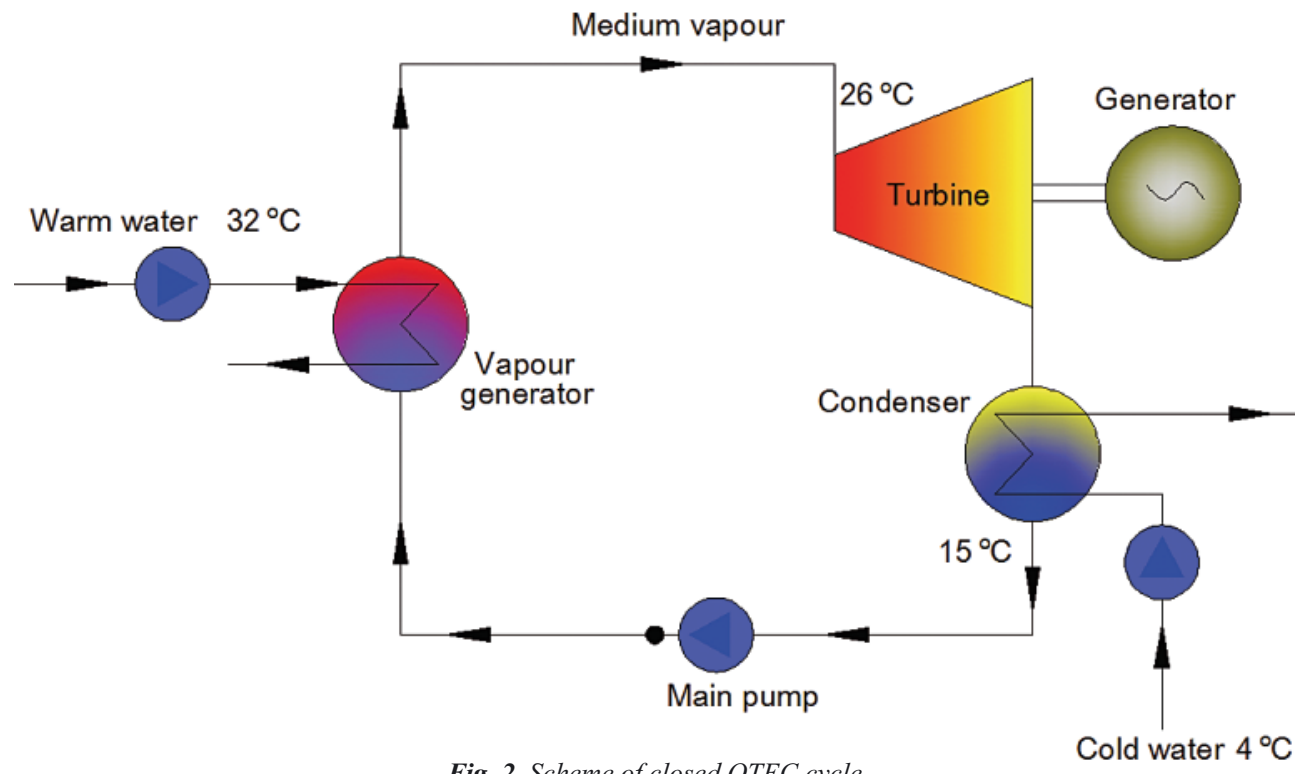

Fig. 2. Scheme of closed OTEC cycle

In each cycle making use of thermal energy of seas and oceans, particular attention is paid to leak tightness of installation components. Due to huge mass flow rates and high requirements for warm and cold water, remarkable part of the produced electric energy is used for covering own needs of the installation, mainly connected with pump feeding. Elimination of leakages to the environment improves the overall efficiency. Both organic and non-organic media can be used in CC-OTEC cycles. Low-boiling media ideally meet conditions for liquids used in those units, and their biggest advantages are low boiling pressure and temperature which is frequently lower than $0^{\circ}$. However, their use is sometimes connected with certain inconveniences, as they reveal, to a smaller or greater extent, flammability and/or toxicity. Their possible direct contact with the environment is highly inadvisable. Advanced protection concerning safety of work, i.e. leakage tightness of the closed cycle, is in this context fully justified.

\section{LOW-BOILING MEDIA}

Working media should meet various requirements which are not connected with their thermal characteristics. First of all, they should not be toxic and should be environment friendly. They should be cheap and easily accessible. They cannot react with flow system components. A properly selected low-boiling medium should provide opportunities for system operation at highest possible efficiency, and for maximal possible utilisation of the available heat source. Other very important criteria which are to be met by the working medium and are to be taken into account in its selection include: low freezing temperature, high critical temperature, corrosion passiveness, lack of toxicity, incombustibility, low price, etc. Moreover, it is important for the working medium not to produce any threat for human beings and the environment. The effect of a given medium on the environment is measured using ecological coefficients, mainly ODP (Ozone Depletion Potential) and GWP (Global Warming Potential).

\section{ASSESSMENT OF RESULTS OF CALCULATIONS OF CIRCUM- EQUATORIAL OTEC CYCLE}

Within the framework of the present analysis, calculations were performed for the closed OTEC cycle working in conditions characteristic for circum-equatorial regions (see
Fig. 2). The temperatures of the media assumed for the calculations are shown in the figure. The next assumption was the mass flow rate of $100 \mathrm{~kg} / \mathrm{s}$ used for vapour production in the evaporator. For the closed OTEC cycle power plant several tens of media were analysed, after which more than ten media securing high cycle efficiency and technical realisability were selected $[10,11,19]$. The below presented results refer to the following selected media: Water, Acetone, Methanol, Isobutane, Dimethyl ether, R114, R227ea, R245fa, Trifluoroiodomethane, R124, R1234ze, Ammonia. For each medium the pressure at turbine inlet was optimised in such a way that maximum power was reached, and the heat exchanger design was technically realisable.

From the warm water mass flow rate equal to $100 \mathrm{~kg} / \mathrm{s}$ we can produce, approximately, from 48 to $50 \mathrm{~kW}$ of turbine shaft power (see Fig. 3), which corresponds to cycle efficiency not exceeding $2.9 \%$ (see Tab. 2). The power outputs obtained in the analysis were close to each other, therefore medium selection should be based on other parameters which would secure designing a cheap, reliable, and highly efficient installation. The experience gained in Japanese experiments suggests that the costs of the working medium, turbine, pumps and heat exchangers amount to as much as about $20 \%$. In this situation attempts are to be made for the turbine cycle units to be properly optimised. Main attention was focused here on optimisation of the design parameters of the turbine working with selected low-boiling media [14].

The analysis included optimisation of design parameters for a single-stage axial turbine with respect to the generated power output. The optimised parameters were the following: velocity coefficient, reaction, rotational speed, and supply arc dimension. An attempt was also made to keep the ratio of the effective diameter to the blade length larger than 4 . Another parameter which was also assessed and taken into account in eth optimisation was the Mach number. Tab. 1 presents a collection of optimal parameters for the singlestage axial turbine. In steam turbines typical values of the velocity coefficient depend on the type of the turbine stage and range from 0.4 to 0.5 for impulse stages, and even as much as from about 0.6 to 0.7 for reaction stages. For the analysed media the selected velocity coefficient not exceeded 0.6 (see Fig. 4), which is a typical range for systems of this type. The stage reaction was selected in such a way that the peripheral efficiency was the highest possible, keeping at the same time the hub reaction not larger than 0.05 . Typical reaction used in 


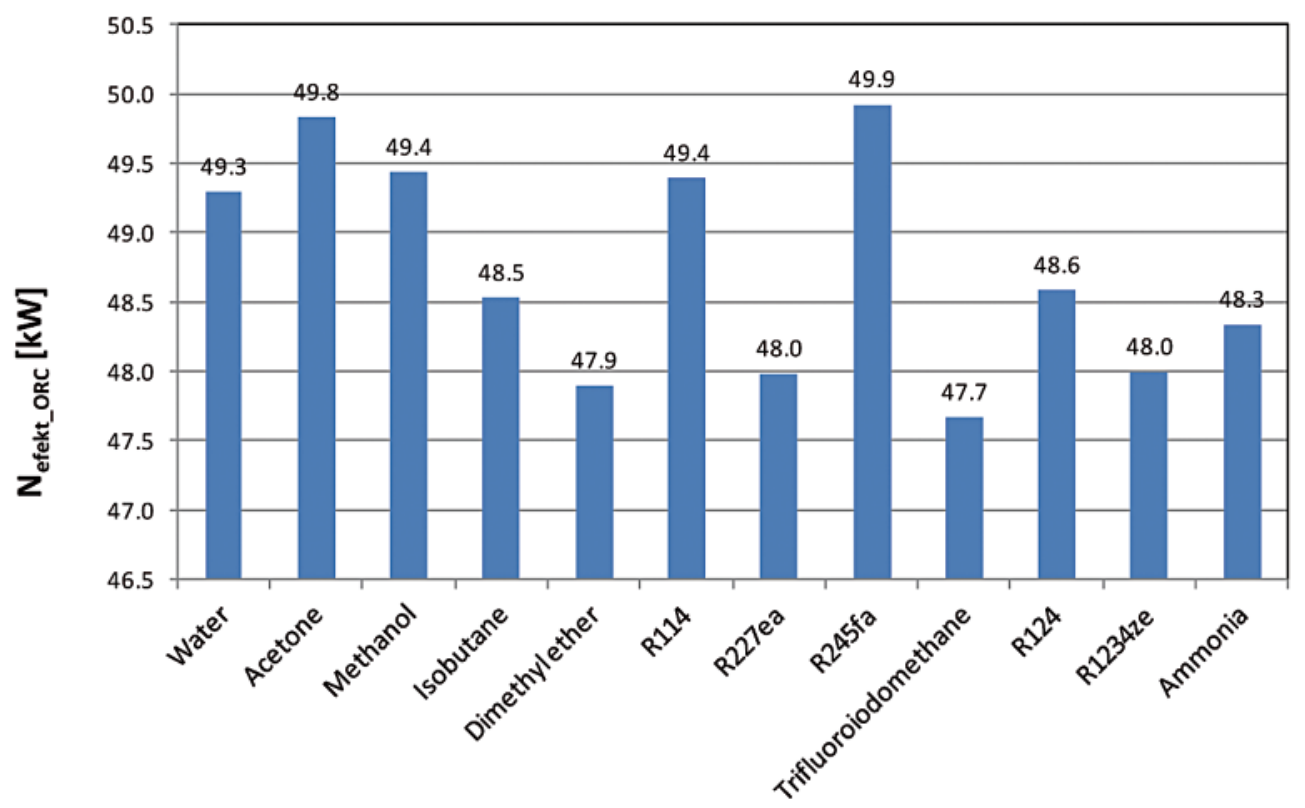

Fig. 3. Turbine shaft power for the examined media

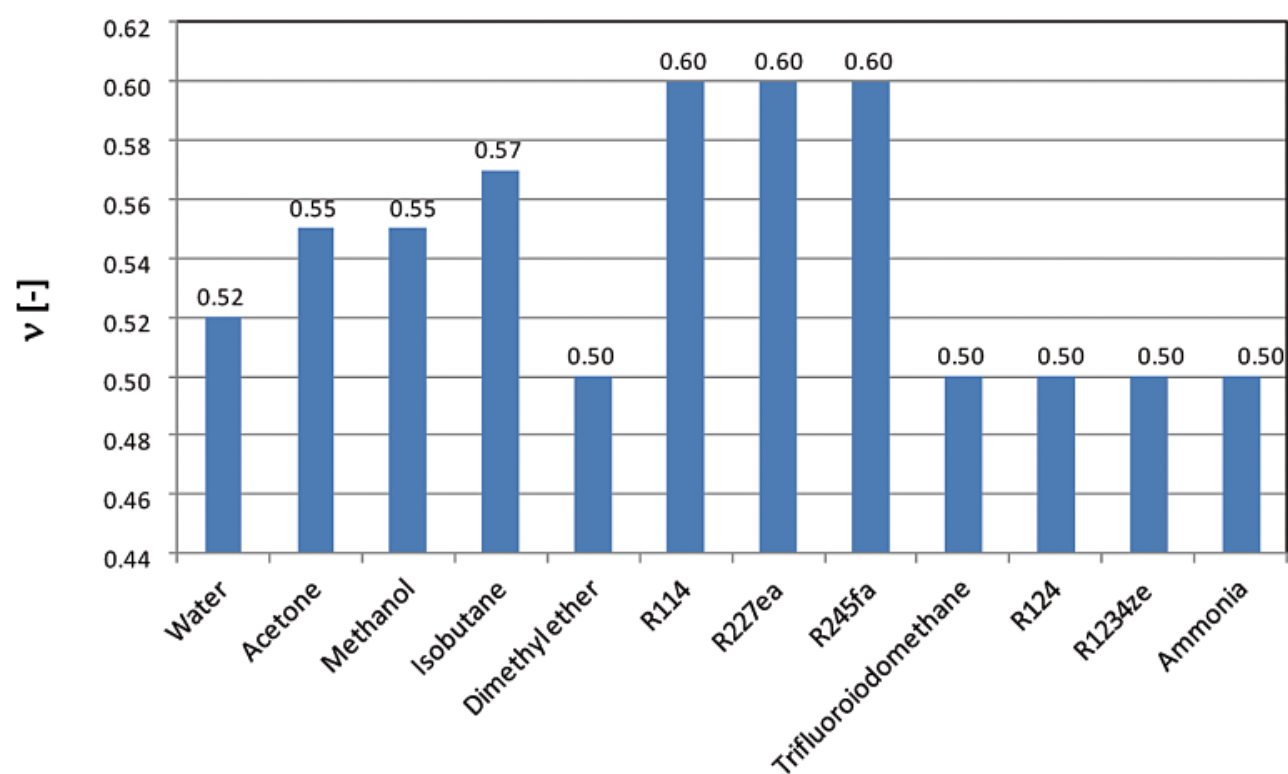

Fig. 4. Single-stage turbine velocity coefficient for the examined media

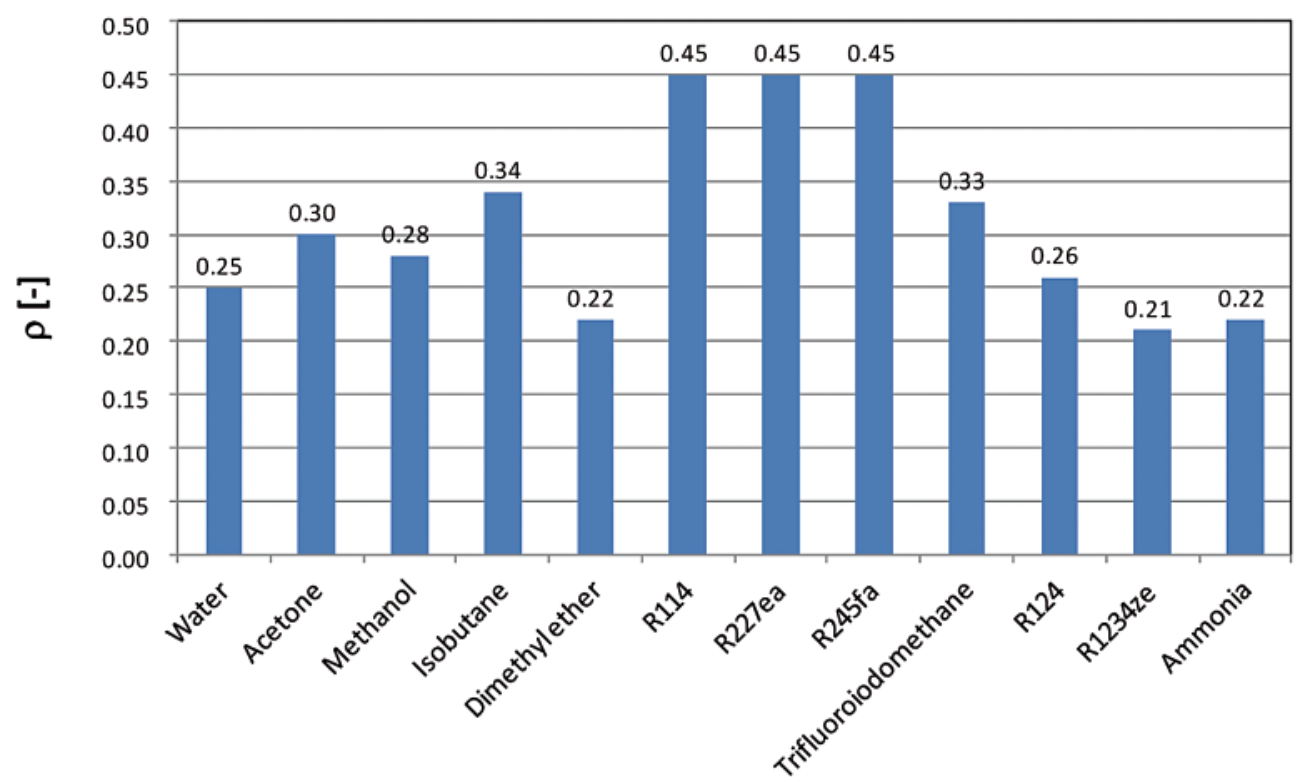

Fig. 5. Single-stage turbine reaction for the examined media 
turbine stages does not exceed 0.7. During the present analysis the stage reaction did not exceed 0.5 (see Fig. 5), i.e. it also took typical values [12]. The rotational speed obtained in the analysis depended on the type of medium and was equal to 3000 and $6000 \mathrm{rpm}$ for most media, while for Trifluoroiodomethane and Ammonia it was equal to 15000 and $16000 \mathrm{rpm}$, respectively (see Fig. 6). All these values are acceptable for technical realisation. In most cases full supply arc was reached, only for Trifluoroiodomethane it did not exceed $5 \%$ (see Table 2). Reduction of the supply arc dimension increases remarkably the ventilation loss and decreases the internal stage work. This result, combined with slightly lower efficiency eliminates the above medium as a working medium.

The turbine was designed in such a way as to obtain the length of the blades not smaller than $10 \mathrm{~mm}$ and the $\mathrm{D} / \mathrm{L}$ ratio not lower than 4 (see Fig. 7 and Fig. 8). This condition was met for the reported media. The selected design parameters should have secured not exceeding 1 by the Mach number at stator and rotor exits. This condition was also met, and in each case subsonic stages were obtained (see Fig. 9 and Fig. 10). The performed analysis has proved that a highly efficient singlestage axial turbine can be designed for most of the examined media (excluding Trifluoroiodomethane). However, it seems that very low pressure (high negative pressure) eliminates water, acetone and methanol. In this situation, the media which looks most favourable from the technical point of view are R114, R245fa and Ammonia. Here, other criteria are to be taken into account, including toxicity of the medium (safety in case of leakage) and its effect on the environment. A detailed and realistic economic analysis is also to be performed. Final selection of a relevant medium will be a compromise between the advantages and disadvantages of this medium.

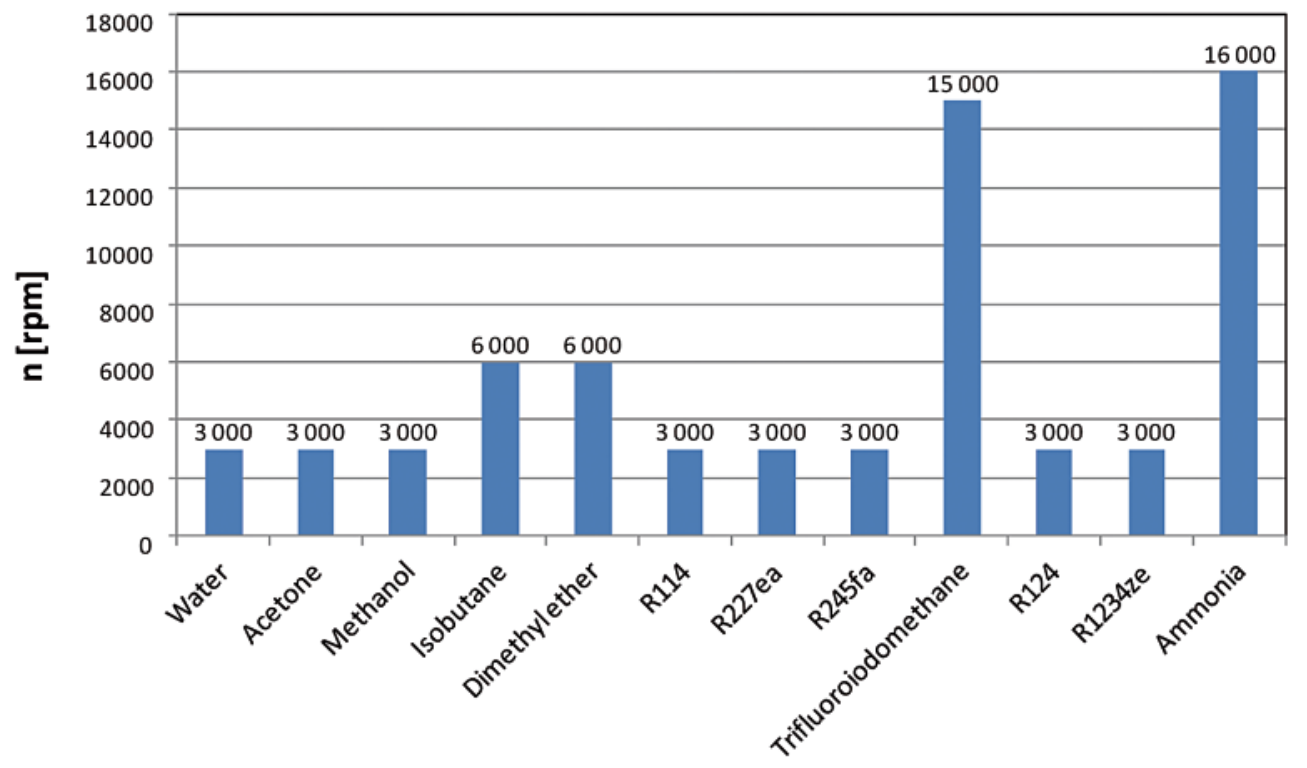

Fig. 6. Single-stage turbine rotational speed for the examined media

Tab. 2. Comparison of calculated results for closed OTEC power plant with turbine design parameters; where: $N_{\text {efekt_oRC-effective power of the cycle; }}$ $\eta_{\text {par }}$-cycle efficiency; $\eta_{\text {carnot }}$-Carnot cycle efficiency; $p_{0}$-medium vapour pressure at turbine inlet; $m_{\text {opary }}$-medium vapour mass flow rate; $H_{S}$-isentropic enthalpy drop in the turbine; $v$-velocity coefficient; $\rho$-stage reaction; $M a_{c l}$-Mach number at stage stator exit; $\varepsilon_{-}$-supply arc dimension; $n$-rotational speed; $D_{\text {s. }}$-mean stage diameter; $l_{k}$-stator blade length; D/l-mean diameter-to-blade length ratio; $M a_{w 2}$-Mach number at stage rotor exit

\begin{tabular}{|c|c|c|c|c|c|c|c|c|c|c|c|c|c|c|c|}
\hline Parameter & $\mathbf{N}_{\text {efekt_ORC }}$ & $\eta_{\text {par }}$ & $\boldsymbol{\eta}_{\text {carnot }}$ & $\mathbf{p}_{0}$ & $\mathbf{m}_{\text {0pary }}$ & $\mathbf{H}_{\mathrm{s}}$ & $v$ & $\rho$ & $\mathbf{M a}_{\mathrm{c} 1}$ & $\varepsilon$ & n & $\mathbf{D}_{\mathrm{sr}}$ & $I_{k}$ & $\mathrm{D} / \mathrm{l}$ & $\mathbf{M a}_{\mathrm{w} 2}$ \\
\hline $\begin{array}{l}\text { Medium/ } \\
\text { Unit }\end{array}$ & {$[\mathbf{k W}]$} & {$[-]$} & {$[-]$} & [MPa] & {$[\mathrm{kg} / \mathrm{s}]$} & {$[\mathrm{kJ} / \mathrm{kg}]$} & {$[-]$} & {$[-]$} & {$[-]$} & {$[-]$} & [rpm] & [m] & [m] & {$[-]$} & {$[-]$} \\
\hline Water & 49.29 & 0.0289 & 0.0368 & 0.0033 & 0.686 & 89.81 & 0.52 & 0.25 & 0.24 & 1 & 3000 & 1.403 & 0.126 & 11.1 & 0.17 \\
\hline Acetone & 49.83 & 0.0285 & 0.0368 & 0.0319 & 3.141 & 19.89 & 0.55 & 0.30 & 0.75 & 1 & 3000 & 0.698 & 0.081 & 8.6 & 0.56 \\
\hline Methanol & 49.43 & 0.0288 & 0.0368 & 0.0178 & 1.436 & 43.08 & 0.55 & 0.28 & 0.21 & 1 & 3000 & 1.028 & 0.059 & 17.4 & 0.15 \\
\hline Isobutane & 48.53 & 0.0273 & 0.0368 & 0.3600 & 5.105 & 12.62 & 0.57 & 0.34 & 0.61 & 1 & 6000 & 0.288 & 0.041 & 7.0 & 0.47 \\
\hline $\begin{array}{l}\text { Dimethyl } \\
\text { ether }\end{array}$ & 47.90 & 0.0268 & 0.0368 & 0.6057 & 4.198 & 15.29 & 0.50 & 0.22 & 0.64 & 1 & 6000 & 0.278 & 0.022 & 12.7 & 0.42 \\
\hline R114 & 49.39 & 0.0280 & 0.0368 & 0.2207 & 13.108 & 4.89 & 0.60 & 0.45 & 0.59 & 1 & 3000 & 0.378 & 0.027 & 14.2 & 0.59 \\
\hline R227ea & 47.98 & 0.0267 & 0.0368 & 0.4674 & 15.070 & 4.37 & 0.60 & 0.45 & 0.59 & 1 & 3000 & 0.357 & 0.015 & 23.8 & 0.59 \\
\hline R245fa & 49.92 & 0.0281 & 0.0368 & 0.1533 & 8.830 & 7.22 & 0.60 & 0.45 & 0.62 & 1 & 3000 & 0.459 & 0.023 & 20.0 & 0.63 \\
\hline $\begin{array}{c}\text { Trifluoroiodo- } \\
\text { methane }\end{array}$ & 47.67 & 0.0266 & 0.0368 & 0.5046 & 18.487 & 3.48 & 0.50 & 0.33 & 0.14 & 0.045 & 15000 & 0.053 & 0.010 & 5.4 & 0.11 \\
\hline R124 & 48.58 & 0.0271 & 0.0368 & 0.3934 & 11.472 & 5.64 & 0.50 & 0.26 & 0.67 & 1 & 3000 & 0.338 & 0.034 & 10.1 & 0.47 \\
\hline R1234ze & 47.99 & 0.0267 & 0.0368 & 0.5123 & 10.086 & 6.46 & 0.50 & 0.21 & 0.68 & 1 & 3000 & 0.362 & 0.027 & 13.3 & 0.44 \\
\hline Ammonia & 48.34 & 0.0276 & 0.0368 & 1.0313 & 1.443 & 43.80 & 0.50 & 0.22 & 0.62 & 1 & 16000 & 0.177 & 0.011 & 15.8 & 0.12 \\
\hline
\end{tabular}




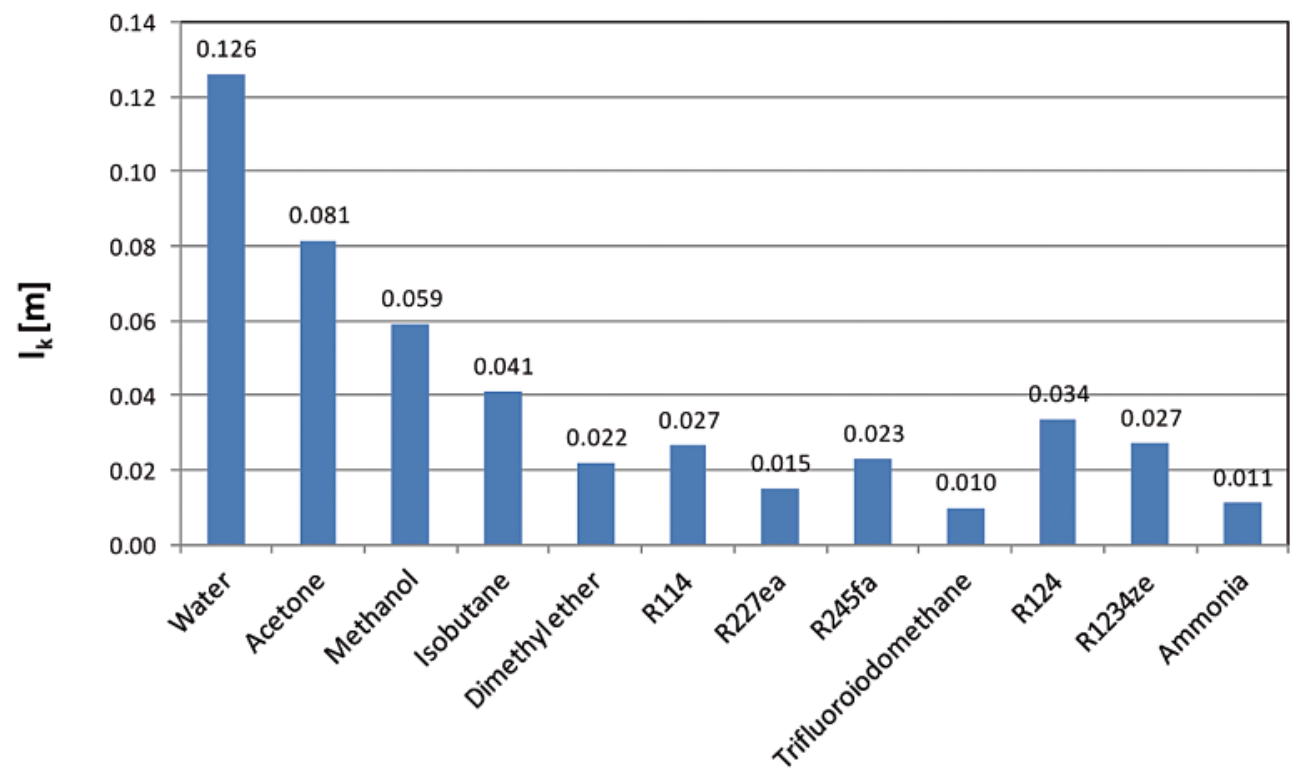

Fig.7. Single-stage turbine stator blade length for the examined media

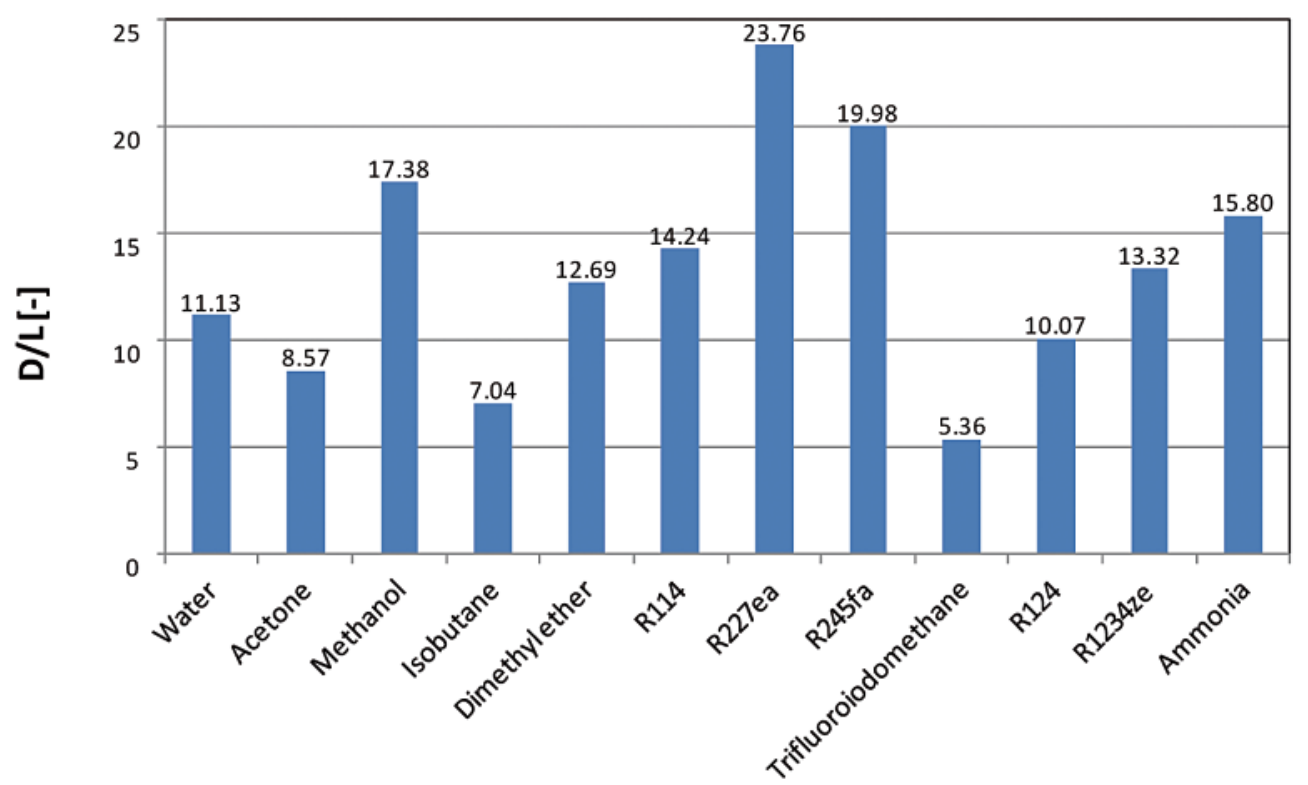

Fig. 8. Single-stage turbine D/L ratio for the examined media

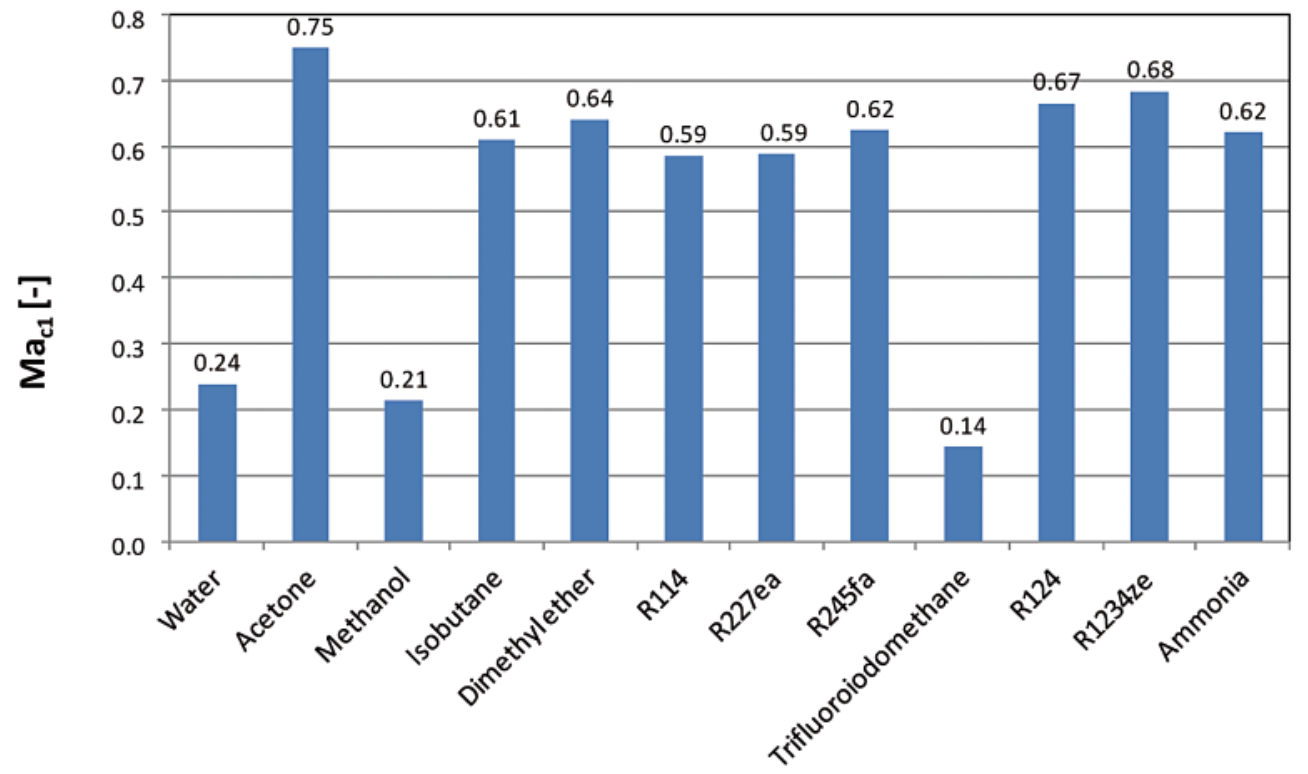

Fig. 9. Absolute Mach number behind single-stage turbine stator for the examined media 


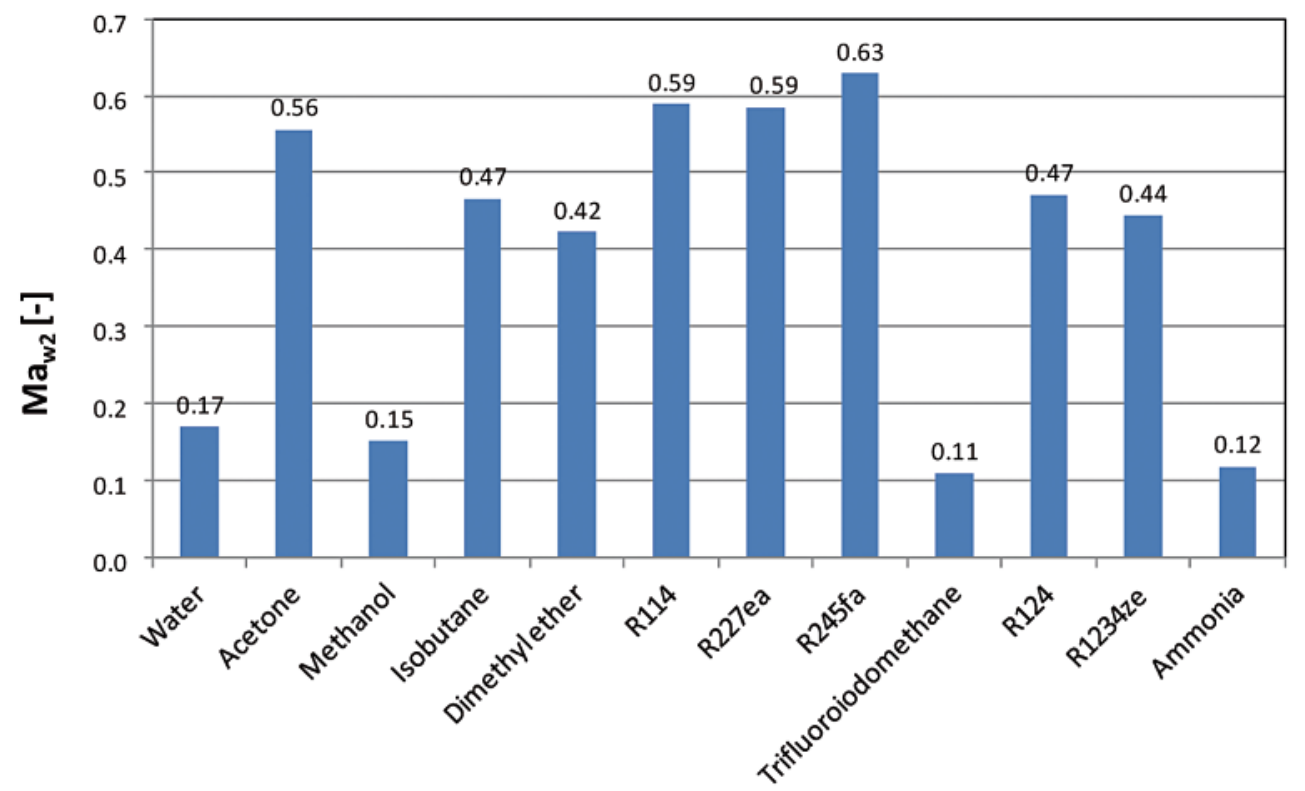

Fig. 10. Relative Mach number behind single-stage turbine rotor

\section{RESULTS OF CALCULATIONS FOR ARCTIC OTEC CYCLE AND THEIR EVALUATION}

For this cycle a system was proposed which makes use of temperature difference between the frosty arctic air and the nonfrozen oceanic water, which eliminates the use of long pipes for its collection. In the cycle shown in Fig. 11 a condenser cooled with frosty air was applied. Other media revealing low freezing temperature, aqueous solution of calcium chloride for instance, can also be applied [1].

The temperatures of the media assumed in arctic OTEC cycle calculations are shown in Fig. 11. The mass flow rate of the non-frozen water which was used for generating medium vapour in the vapour generator was assumed equal to $100 \mathrm{~kg} / \mathrm{s}$. In this case also several tens of media were analysed and, like previously, between ten and twenty media were selected as those which secure high cycle efficiency and technical realisability. Below are presented results of the analysis referring to the selected media, which were: Trifluoroiodomethane, Dimethyl ether, $\mathrm{CO}_{2}, \mathrm{R} 23, \mathrm{R} 13, \mathrm{R} 218$, Sulfur hexafluoride, R116, R245fa, R143a, Ethane, R124, R1234ze and Ammonia. Like in previous case, for each medium the turbine inlet pressure was optimised in such a way that maximum shaft power was obtained for this pressure and the design of the heat exchanger was technically realisable. Approximately, from 30 to $80 \mathrm{~kW}$ of the turbine shaft power can be produced from the assumed mass flow rate of the warm water (see Fig. 12). In the examined arctic variant the obtained power levels differed much between each other. The largest power was produced using Trifluoroiodomethane, Dimethyl ether, and Ammonia as working medium. As for the cycle efficiency, the above list of three media was complemented by R218, R245fa, R124 and R1234ze, for which the recorded efficiency exceeded $6 \%$ (see Tab. 3). In the next step, optimisation of the design parameters for a single-stage axial microturbine was carried out. The list of optimised parameters included: velocity coefficient, reaction, rotational speed, and supply arc dimension. An attempt was made to keep the ratio of the effective diameter to the rotor blade length larger than 4. A parameter which was also assessed and taken into account in the optimisation was the Mach number. Table 3 presents a collection of optimal parameters for the single-stage axial turbine.

The velocity coefficient selected for the analysed media ranged up to 0.7 (see Fig. 13). The stage reaction did not exceed 0.5 (see Fig. 14). During the analyses different rotational speeds

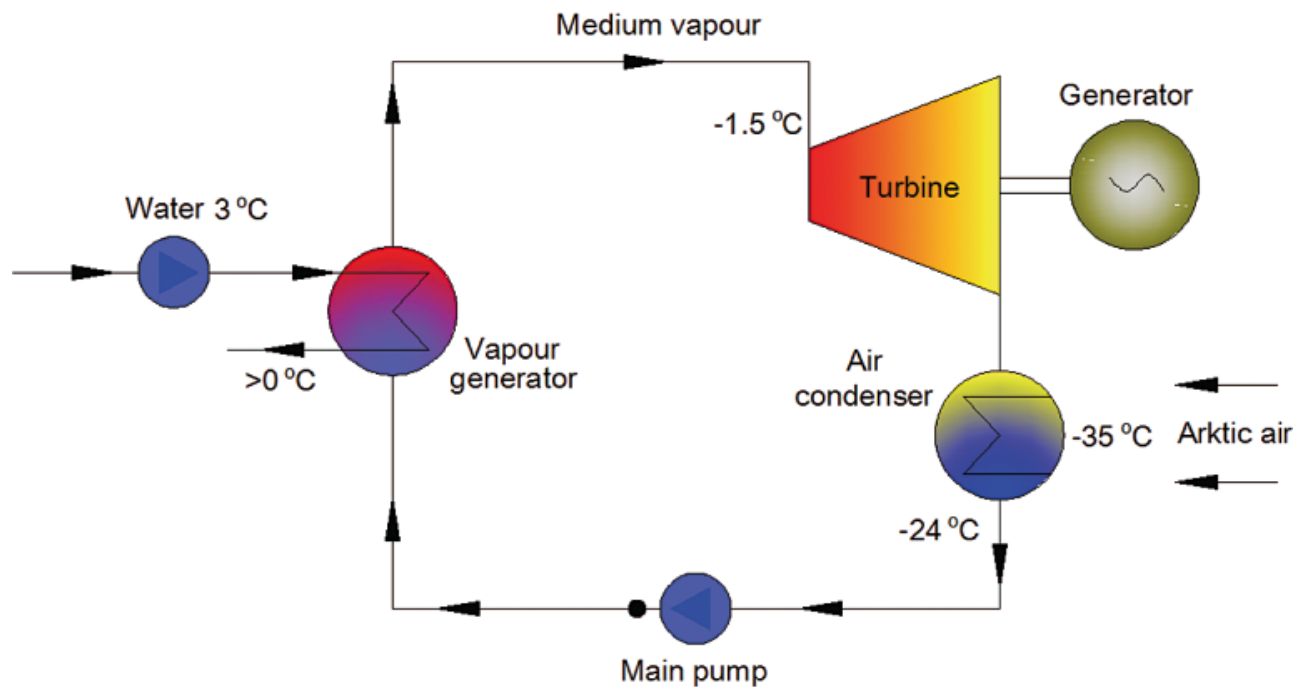

Fig. 11. Scheme of closed OTEC cycle in arctic version 


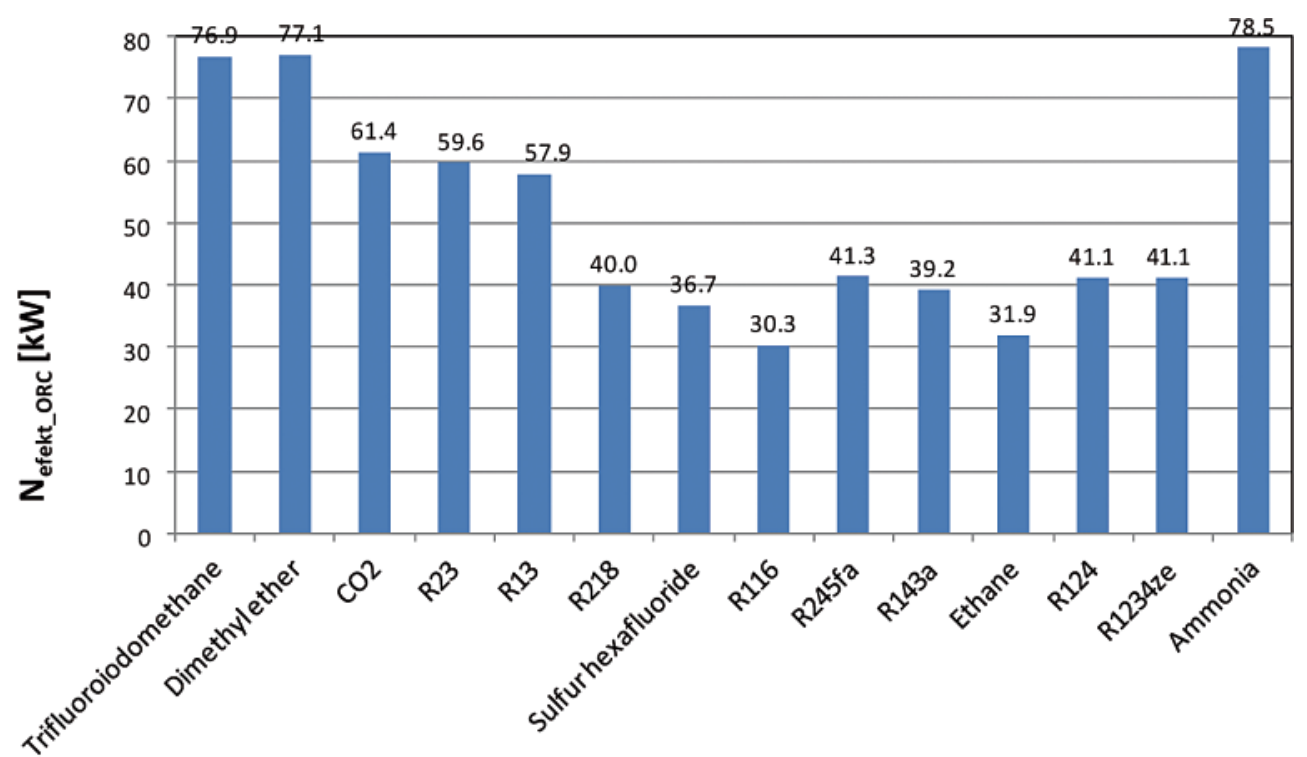

Fig. 12. Turbine shaft power for the examined media

were obtained for different media, they took values from 3000 $\mathrm{rpm}$, to even as much as $37000 \mathrm{rpm}$ for Ammonia (see Fig. 15), which was still technically realisable. In most cases a full supply arc was obtained, excluding Trifluoroiodomethane, Dimethyl ether, Ammonia and Ethane, for which the supply arc dimension did not exceed $20 \%$ (see Table 3 ). In the latter situation the ventilation loss increases remarkable and the internal stage work decreases. The turbine was designed in such a way as to obtain the blade length not smaller than $10 \mathrm{~mm}$ and the D/L ratio not smaller than 4 (see Fig. 16 and Fig. 17). This condition was successfully met for the presented media. The design parameters were selected assuming that the Mach number at turbine stator and rotor exits does not exceed 1 . This condition was also successfully met, and each time a subsonic stage was obtained (see Fig. 18 and Fig. 19). The performed analysis has confirmed that designing a highly efficient singlestage axial turbine is possible for the majority of the analysed media, from which: Trifluoroiodomethane, Dimethyl ether, Ammonia, R218, R245fa, R124 and R1234ze seem to be most favourable from the thermodynamic and technical point of view. If we take into account toxicity of particular media and their effect on the environment (see Tab. 4), the most favourable medium is R245fa which is non-flammable and nontoxic. However, a detailed and realistic economic analysis is to be performed to select finally an optimal medium for the system of this type.

Tab. 3. Comparison of calculation results for arctic OTEC power plant with turbine design parameters; where: $N_{\text {efekt }}$ oRC-effective power of the cycle; $\eta_{\text {par }}$-cycle efficiency; $\eta_{\text {carnot }}$-Carnot cycle efficiency; $p_{0}$ - medium vapour pressure at turbine inlet; $m_{\text {opary }}$-medium vapour mass flow rate; $H_{S}-i$ isentropic enthalpy drop in the turbine; v-velocity coefficient; $\rho$-stage reaction; $M a_{c l}$-Mach number at stage stator exit; $\varepsilon$-supply arc dimension; $n$-rotational speed; $D_{\text {sr }}$-mean stage diameter; $l_{k}$-stator blade length; D/l-mean diameter-to-blade length ratio; $M a_{w 2}$-Mach number at stage rotor exit

\begin{tabular}{|c|c|c|c|c|c|c|c|c|c|c|c|c|c|c|c|}
\hline Parameter & $\mathbf{N}_{\text {efekt_oRC }}$ & $\boldsymbol{\eta}_{\mathbf{p a r}}$ & $\boldsymbol{\eta}_{\text {Carnot }}$ & $\mathbf{p}_{\mathbf{0}}$ & $\mathbf{m}_{\mathbf{0 p a r y}}$ & $\mathbf{H}_{\mathbf{s}}$ & $\mathbf{v}$ & $\boldsymbol{\rho}$ & $\mathbf{M a}_{\mathbf{c} 1}$ & $\boldsymbol{\varepsilon}$ & $\mathbf{n}$ & $\mathbf{D}_{\mathbf{s r}}$ & $\mathbf{I}_{\mathbf{K}}$ & $\mathbf{D} / \mathbf{l}$ & $\mathbf{M a}_{\mathbf{w} \mathbf{2}}$ \\
\hline Medium/Unit & {$[\mathbf{k W}]$} & {$[-]$} & {$[-]$} & {$[\mathbf{M P a}]$} & {$[\mathbf{k g} / \mathbf{s}]$} & {$[\mathbf{k J} / \mathbf{k g}]$} & {$[-]$} & {$[-]$} & {$[-]$} & {$[-]$} & {$[\mathbf{r p m}]$} & {$[\mathbf{m}]$} & {$[\mathbf{m}]$} & {$[-]$} & {$[-]$} \\
\hline $\begin{array}{c}\text { Trifluoroiodo- } \\
\text { methane }\end{array}$ & 76.86 & 0.0615 & 0.0828 & 0.2158 & 11.31 & 8.70 & 0.50 & 0.30 & 0.18 & 0.10 & 12000 & 0.105 & 0.010 & 10.37 & 0.13 \\
\hline Dimethyl ether & 77.11 & 0.0617 & 0.0828 & 0.252 & 2.56 & 38.43 & 0.49 & 0.22 & 0.21 & 0.20 & 27000 & 0.096 & 0.010 & 9.70 & 0.69 \\
\hline CO2 & 61.37 & 0.0491 & 0.0828 & 3.34 & 4.42 & 23.17 & 0.50 & 0.23 & 0.82 & 1.00 & 23000 & 0.089 & 0.010 & 8.69 & 0.56 \\
\hline R23 & 59.59 & 0.0479 & 0.0828 & 2.3885 & 7.12 & 14.18 & 0.66 & 0.28 & 0.30 & 1.00 & 3000 & 0.708 & 0.108 & 6.56 & 0.21 \\
\hline R13 & 57.90 & 0.0466 & 0.0828 & 1.8885 & 10.64 & 9.44 & 0.70 & 0.35 & 0.29 & 1.00 & 3000 & 0.612 & 0.124 & 4.93 & 0.23 \\
\hline R218 & 39.96 & 0.0611 & 0.0828 & 0.3934 & 6.24 & 8.55 & 0.55 & 0.45 & 0.89 & 1.00 & 6000 & 0.229 & 0.027 & 8.58 & 0.82 \\
\hline $\begin{array}{c}\text { Sulphur } \\
\text { hexafluoride }\end{array}$ & 36.72 & 0.0533 & 0.0828 & 1.1974 & 6.59 & 8.31 & 0.52 & 0.32 & 0.91 & 1.00 & 9000 & 0.142 & 0.016 & 8.89 & 0.68 \\
\hline R116 & 30.31 & 0.0415 & 0.0828 & 1.7673 & 7.92 & 7.26 & 0.50 & 0.30 & 0.32 & 1.00 & 9000 & 0.128 & 0.014 & 8.96 & 0.68 \\
\hline R245fa & 41.30 & 0.0627 & 0.0828 & 0.0492 & 2.86 & 18.17 & 0.55 & 0.47 & 0.99 & 1.00 & 4500 & 0.445 & 0.061 & 7.31 & 0.97 \\
\hline R143a & 39.21 & 0.0584 & 0.0828 & 0.5893 & 3.03 & 17.30 & 0.49 & 0.30 & 0.24 & 1.00 & 11000 & 0.158 & 0.018 & 8.82 & 0.17 \\
\hline Ethane & 31.90 & 0.0462 & 0.0828 & 2.2955 & 1.82 & 30.84 & 0.50 & 0.22 & 0.27 & 0.50 & 21000 & 0.113 & 0.012 & 9.48 & 0.55 \\
\hline R124 & 41.15 & 0.0621 & 0.0828 & 0.1534 & 3.65 & 14.35 & 0.55 & 0.45 & 0.92 & 1.00 & 6000 & 0.297 & 0.036 & 8.14 & 0.87 \\
\hline R1234ze & 41.11 & 0.0617 & 0.0828 & 0.204 & 3.17 & 16.59 & 0.49 & 0.40 & 0.96 & 1.00 & 6000 & 0.284 & 0.027 & 10.50 & 0.85 \\
\hline Ammonia & 78.45 & 0.0630 & 0.0828 & 0.4043 & 0.91 & 109.32 & 0.50 & 0.50 & 0.19 & 0.16 & 37000 & 0.121 & 0.010 & 12.10 & 0.82 \\
\hline
\end{tabular}




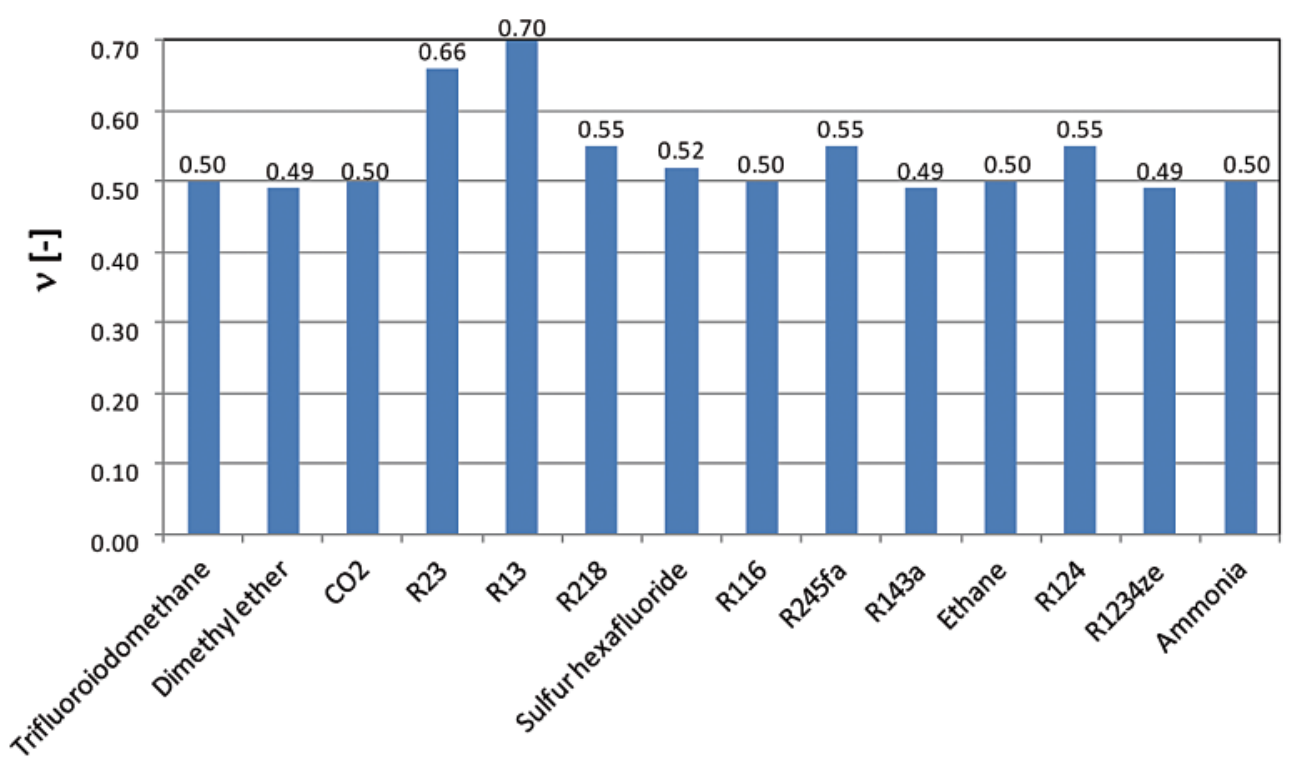

Fig. 13. Single-stage turbine velocity coefficient for the examined media

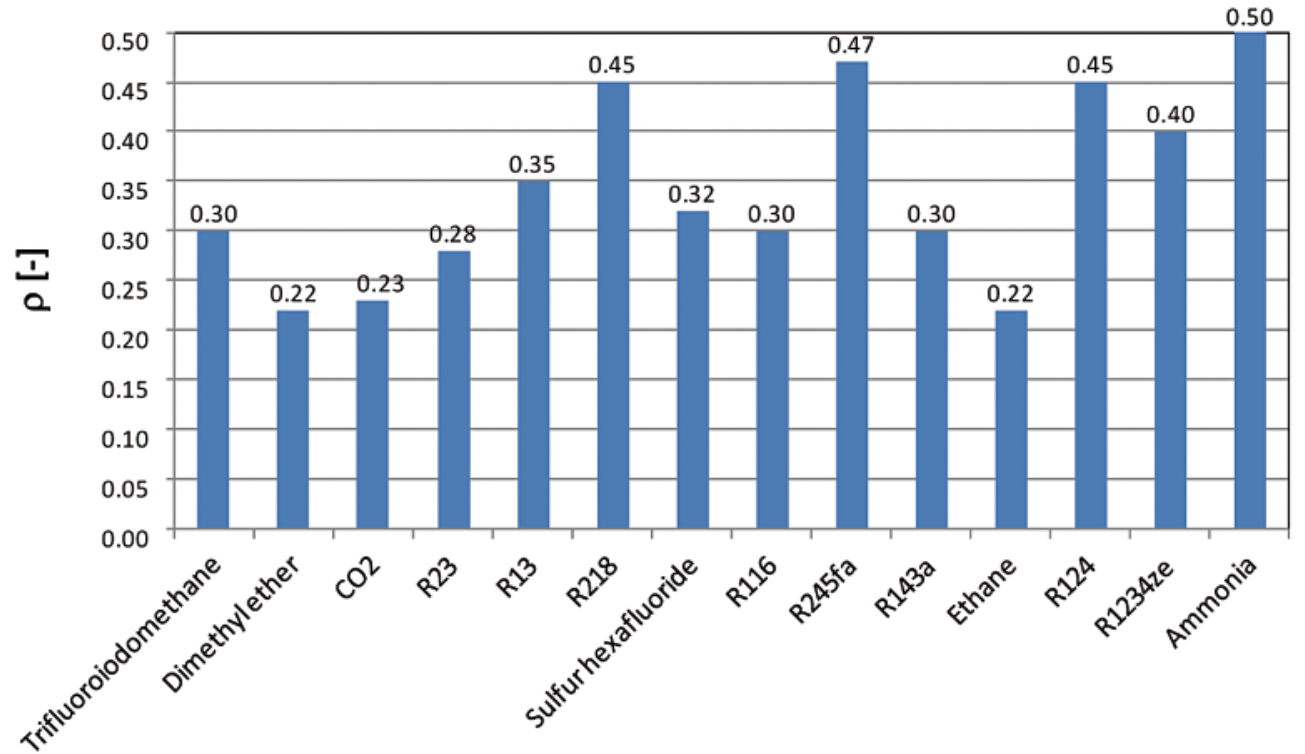

Fig. 14. Single-stage turbine reaction for the examined media

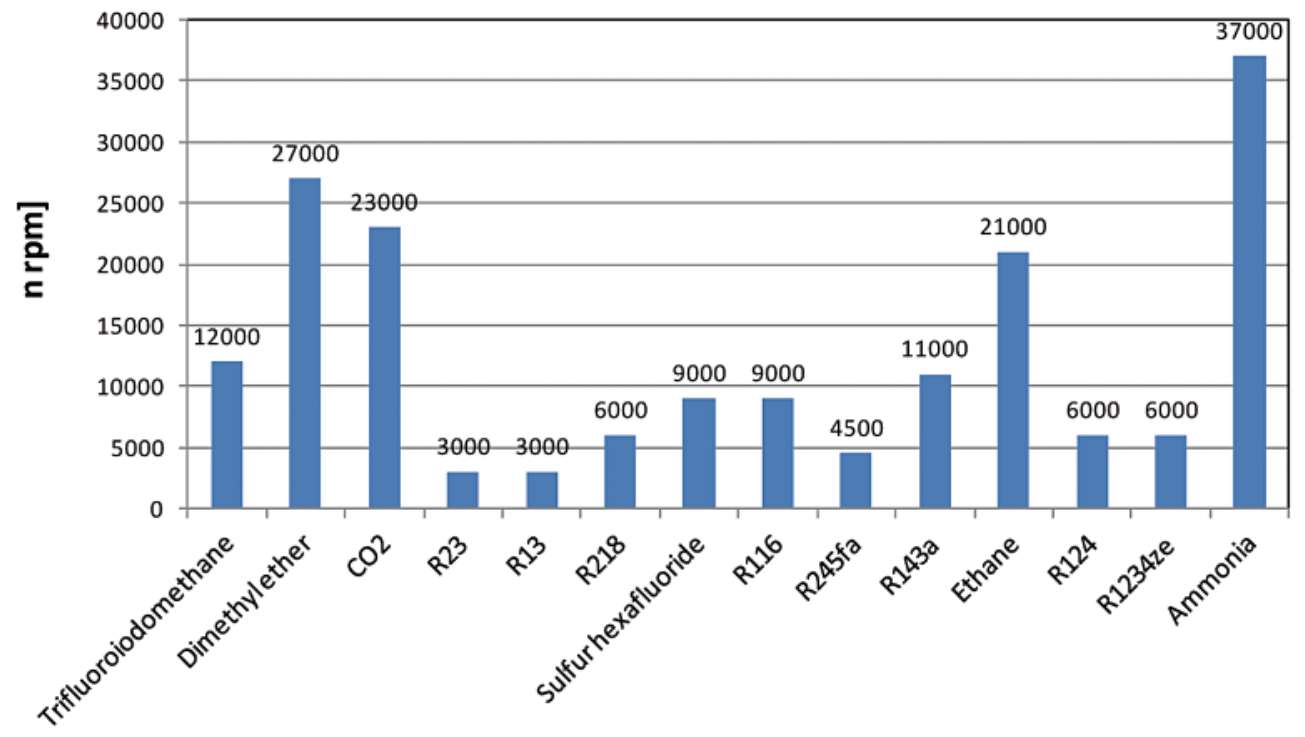

Fig. 15. Single-stage turbine rotational speed for the examined media 


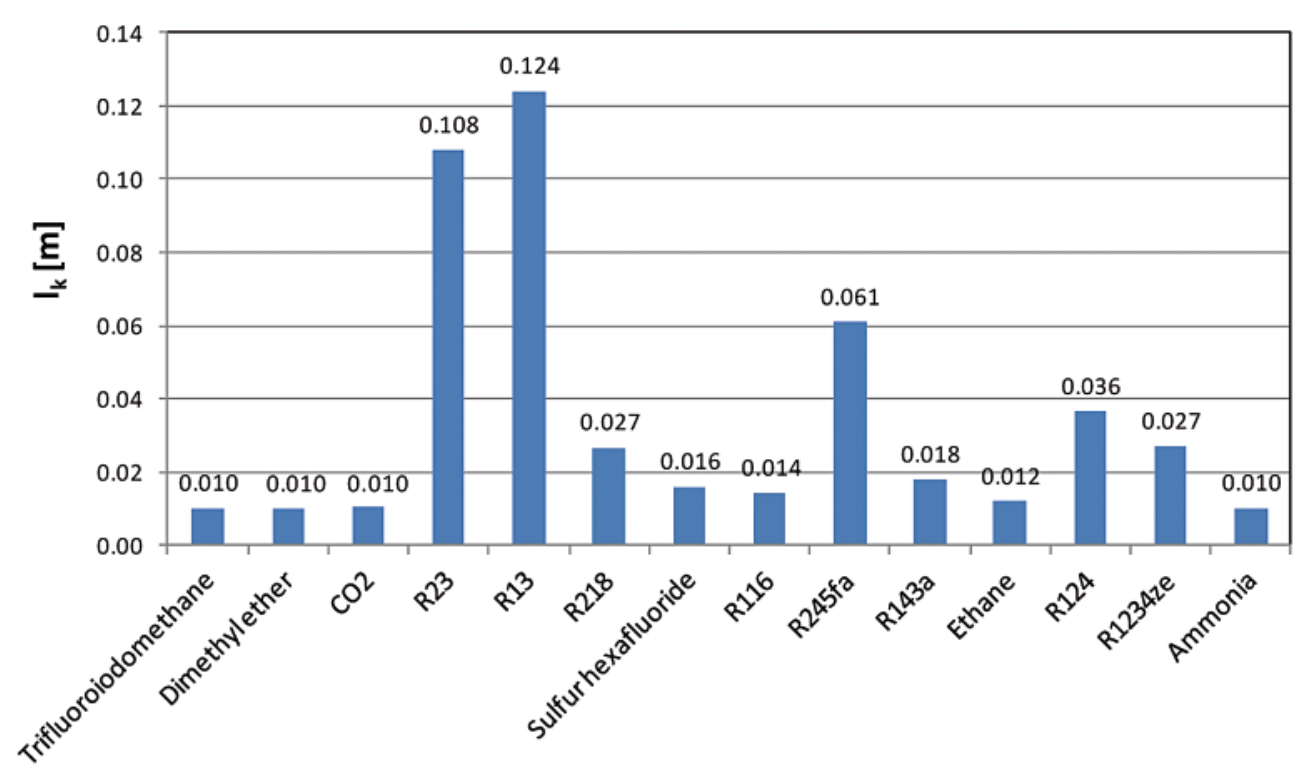

Fig. 16. Single-stage turbine stator blade length for the examined media

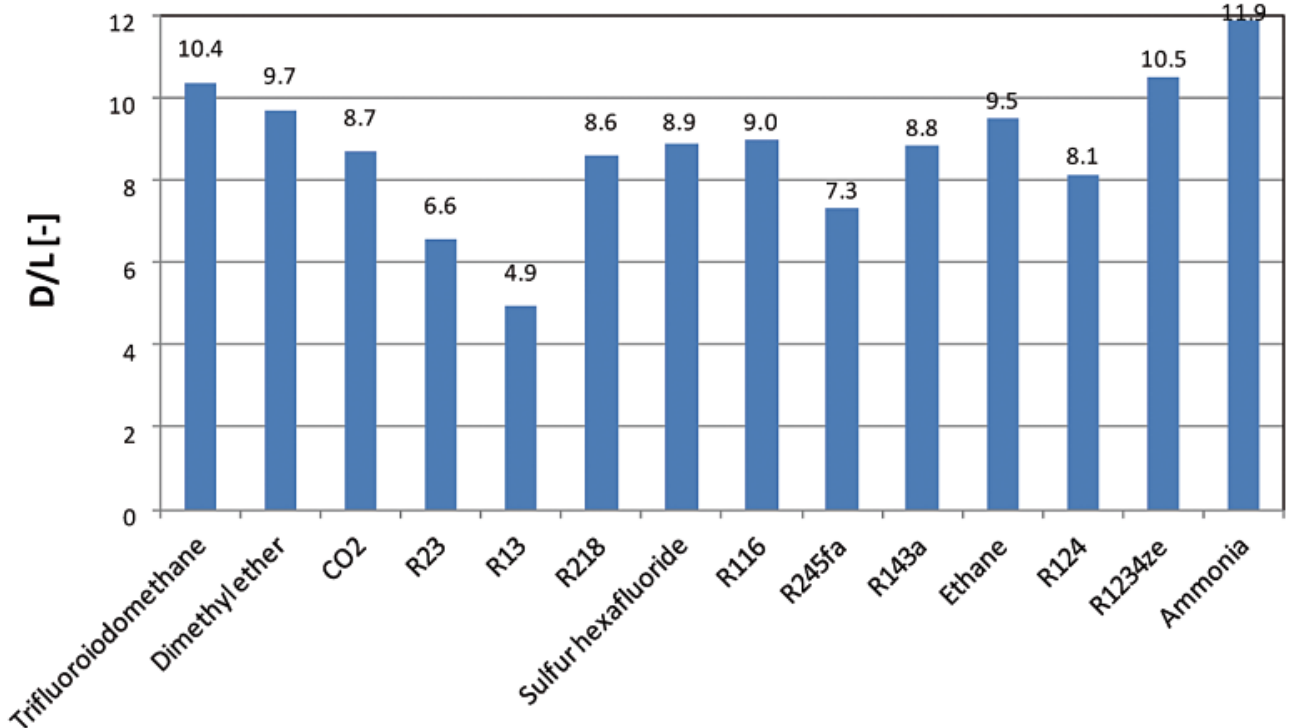

Fig. 17. Single-stage turbine D/L ratio for the examined media

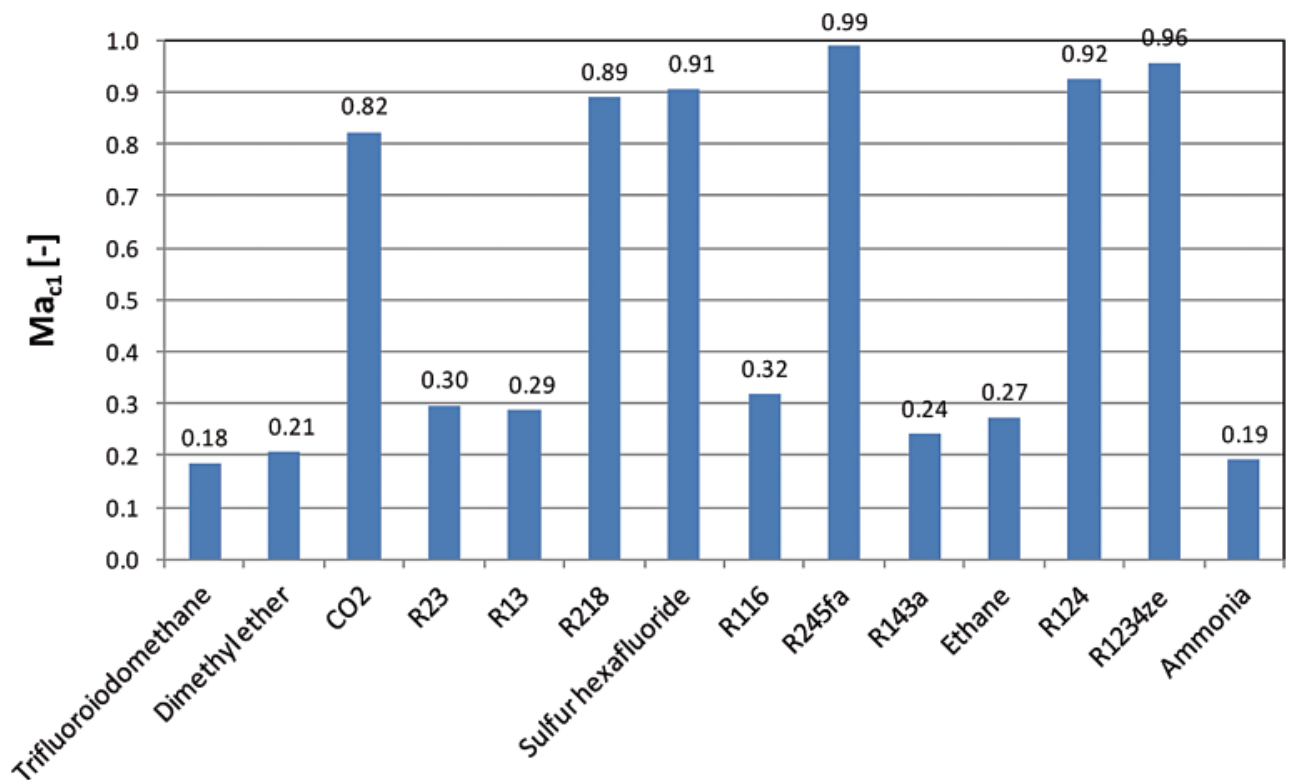

Fig. 18. Absolute Mach number behind single-stage turbine stator for the examined media 


\begin{tabular}{|c|c|c|c|c|c|c|c|c|c|c|c|c|c|c|c|c|c|}
\hline$\frac{\infty}{\widetilde{\approx}}$ & 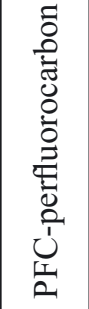 & 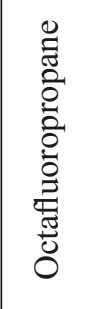 & $\mathcal{L}^{\infty}$ & $\begin{array}{l}8 \\
\text { D } \\
\text { i }\end{array}$ & $\begin{array}{l}\widetilde{0} \\
\infty \\
\infty \\
\infty\end{array}$ & $\mid \begin{array}{l}0 \\
\infty \\
i \\
i\end{array}$ & $\begin{array}{l}t \\
\dot{i} \\
i\end{array}$ & $\begin{array}{l}0 \\
\vdots \\
8 \\
0\end{array}$ & $\stackrel{\Re}{\varrho}$ & 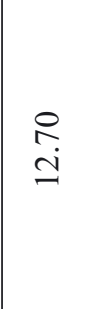 & 0 & § & 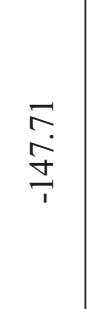 & $\underset{\text { Sิ }}{\tilde{i}}$ & 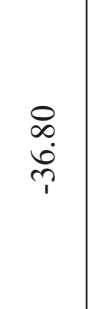 & 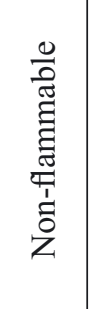 & 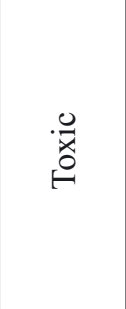 \\
\hline 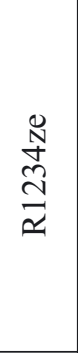 & 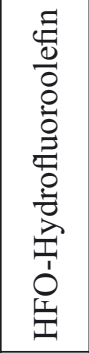 & 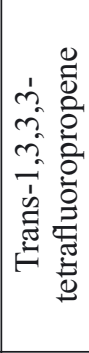 & 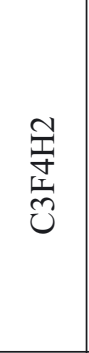 & $\stackrel{n}{0}$ & $\begin{array}{l}\stackrel{\Xi}{O} \\
\dot{\Xi} \\
=\end{array}$ & 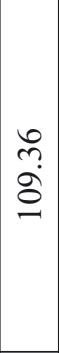 & $\begin{array}{l}\tilde{\sigma} \\
\dot{m}\end{array}$ & 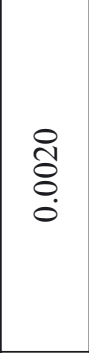 & ڤે & $\begin{array}{l}\stackrel{\infty}{n} \\
\stackrel{n}{n}\end{array}$ & 0 & 6 & $\begin{array}{l}\stackrel{0}{n} \\
\stackrel{0}{0} \\
\end{array}$ & $\frac{\stackrel{\infty}{N}}{\stackrel{\sim}{ה}}$ & $\frac{\hat{\alpha}}{\infty}$ & 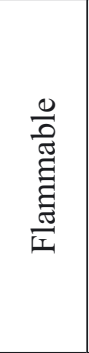 & $\stackrel{0}{\stackrel{0}{x}}$ \\
\hline$\stackrel{\Xi}{\Xi}$ & 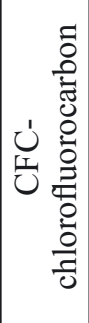 & 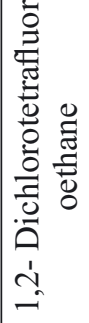 & $\begin{array}{l}\overrightarrow{U^{+}} \\
\tilde{I}^{+} \\
U^{\prime}\end{array}$ & ষ্ণ & مa & 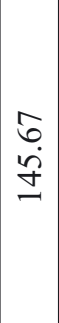 & 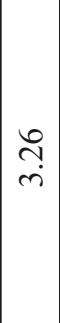 & $\begin{array}{l}\frac{1}{8} \\
\dot{8}\end{array}$ & $\begin{array}{l}\text { f. } \\
\stackrel{0}{0}\end{array}$ & $\stackrel{8}{\stackrel{8}{=}}$ & - & § & ' & & $\begin{array}{l}\infty \\
n \\
m\end{array}$ & 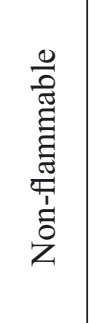 & $\stackrel{0}{\stackrel{0}{x}}$ \\
\hline 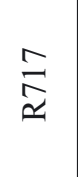 & & 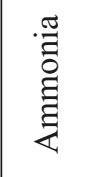 & $\vec{z}$ & $\stackrel{\partial}{\circ}$ & $\stackrel{o}{\underline{\sigma}}$ & 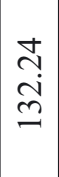 & $\stackrel{m}{=}$ & 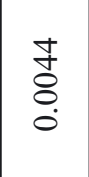 & ๗ેे & $\stackrel{\infty}{\stackrel{\infty}{0}}$ & 0 & 0 & 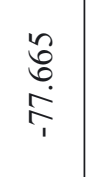 & $\frac{\tilde{1}}{\stackrel{8}{\delta}}$ & $\stackrel{\vec{m}}{m}$ & 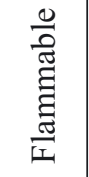 & 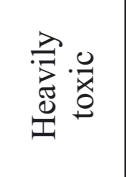 \\
\hline ' & & 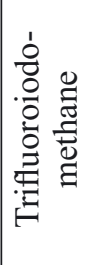 & $\begin{array}{l}\vec{I} \\
\mathrm{U}^{\prime}\end{array}$ & ' & ă & $\stackrel{\mathfrak{I}}{\beth}$ & $\stackrel{n}{\dot{m}}$ & $\begin{array}{l}\frac{1}{8} \\
\stackrel{8}{0} \\
0\end{array}$ & హ. & $\begin{array}{l}\hat{n} \\
\dot{I}\end{array}$ & 0 & ' & $\begin{array}{l}0 \\
\stackrel{0}{n} \\
\stackrel{n}{1}\end{array}$ & $\stackrel{ా}{\circ}$ & $\begin{array}{l}\stackrel{\infty}{\infty} \\
\vec{T}\end{array}$ & 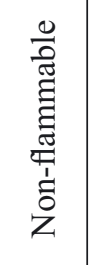 & 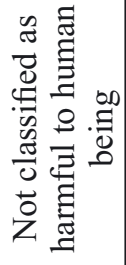 \\
\hline 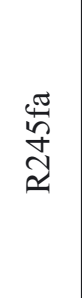 & 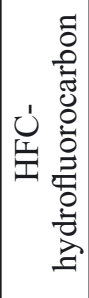 & 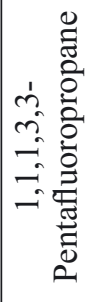 & $\underbrace{I^{n}}_{U^{m}}$ & $\stackrel{\circ}{\sim}$ & $\begin{array}{l}0 \\
\dot{0} \\
\dot{m}\end{array}$ & $\stackrel{+}{n}$ & $\mid \begin{array}{l}n \\
\dot{m}\end{array}$ & $\begin{array}{l}\stackrel{0}{\circ} \\
\stackrel{8}{0} \\
\stackrel{0}{0}\end{array}$ & $\hat{\tilde{N}}$ & 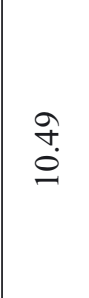 & 0 & లి & 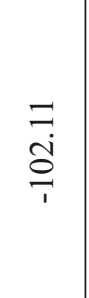 & $\begin{array}{l}\vec{n} \\
\stackrel{\Omega}{\simeq}\end{array}$ & $\frac{m}{n}$ & 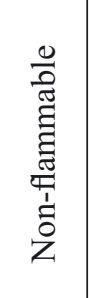 & 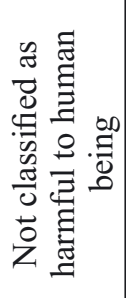 \\
\hline$\frac{?}{\frac{P}{2}}$ & 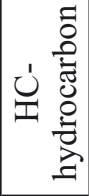 & 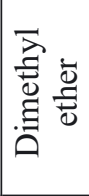 & 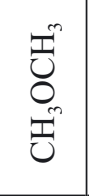 & $\stackrel{n}{\circ}$ & $\begin{array}{l}\hat{S} \\
\dot{b} \\
\dot{f}\end{array}$ & 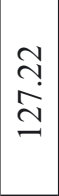 & $\begin{array}{l}\dot{m} \\
m \\
i n\end{array}$ & 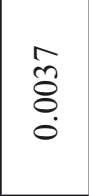 & $\begin{array}{l}\stackrel{n}{n} \\
\stackrel{0}{\infty} \\
-\infty\end{array}$ & స్ & 0 & 0 & $\frac{\vec{n}}{\frac{7}{7}}$ & $\overrightarrow{\widetilde{i}}$ & 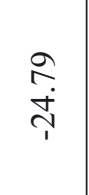 & 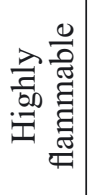 & 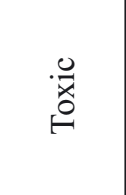 \\
\hline & & & & 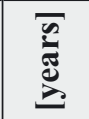 & 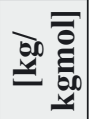 & $\underline{\bar{v}}$ & $e^{\bar{\pi}}$ & 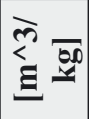 & 咅 & 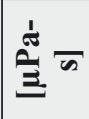 & I & $I$ & $\underline{\bar{v}}$ & $\underline{\tilde{\sigma}}$ & $\underline{\bar{v}}$ & & \\
\hline 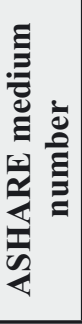 & 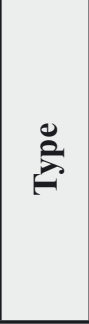 & 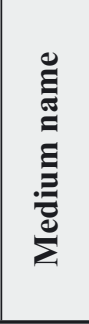 & 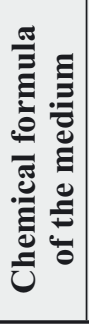 & 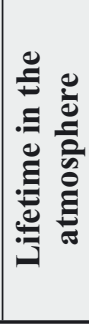 & 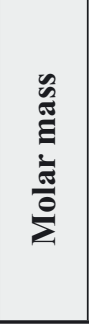 & 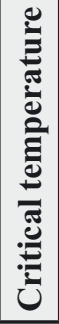 & 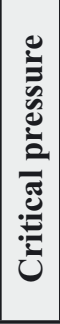 & 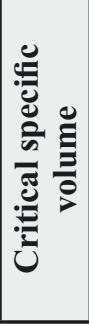 & 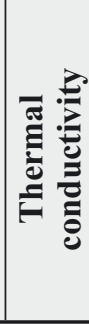 & 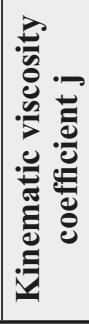 & 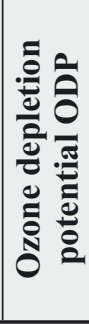 & 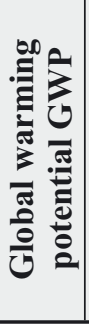 & 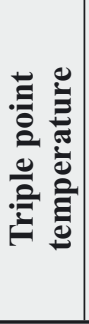 & 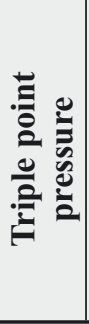 & 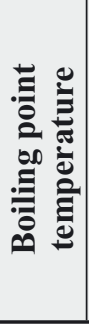 & 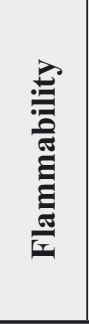 & 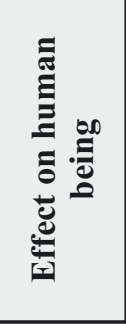 \\
\hline
\end{tabular}




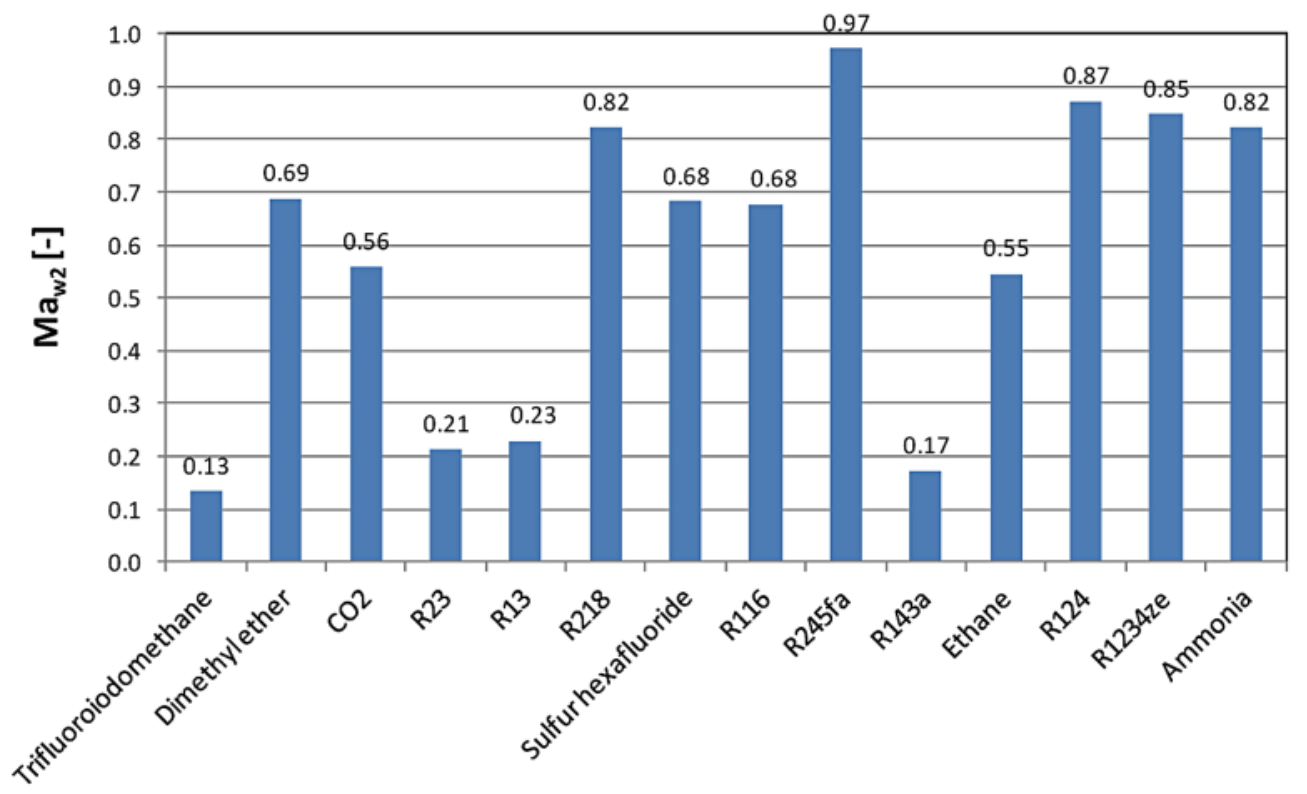

Fig. 19. Relative Mach number behind single-stage turbine rotor for the examined media

\section{CONCLUSIONS}

To sum up, OTEC power plants are the source of clean and renewable electric energy. Along with the energy they can produce fresh water, which is of high importance in the areas with its shortages. A properly designed system generates limited, or even zero amount of carbon dioxide. It is optimistically estimated that the resources of thermal energy are so high that they can meet all current power requirements of the human society. Its disadvantage still remains high production cost, which is remarkably higher than in case of energy production from coal. For the operation of this type of power plant to be possible, the temperature difference between the upper and lower heat source should reach about $20{ }^{\circ} \mathrm{C}$, the least. Moreover, vast resources of cold water should be situated close to the land for large power plants to be erected in the vicinity of human agglomerations. Up to the present, certain problems can be observed with collecting financial support for such actions, as only small-scale systems have been tested so far. Another disadvantage is unfavourable effect of on the environment, as localisation of power plants (pipes with warm and cold water) close to the land unfavourably affects the offshore marine ecosystem and reefs. The here reported analysis has proved that constructing a system which utilises thermal energy stored in oceans is possible. It has also turned out that higher potential is this field can be found in the circumpolar regions. For the assumed mass flow rate of the water used for producing the organic medium vapour, certain media were proposed which secured installation efficiency exceeding $6 \%$. This result does not seem impressive, but the source of this energy is practically inexhaustible.

For a group of low-boiling media a preliminary design of the axial turbine was presented. The realistic ranges of the selected design parameters have proved that constructing a highly efficient turbine making use of low-boiling medium is possible.

\section{BIBLIOGRAPHY}

1. Akulichev V., Ilyin A., Tikmenov V.A. Possibility of Using OTEC Systems in Arctic Regions, OCEANS ‘83, Proceedings, Aug. 29 1983-Sept. 1 1983;

2. Bogdanienko J. Renewable energy sources (in Polish), PWN, Warsaw, 1989;
3. Breeze P. Power Generation Technologies, ISBN 075066313 8, Elsevier's Science and Technology Rights Department in Oxford, London, UK, 2005;

4. Chong H-Y., Lam W-H. Ocean renewable energy in Malaysia The potential of the Straits of Malacca, Renewable and Sustainable Energy Reviews 23, 2013;

5. Cohen R. Energy from the ocean, Phil. Trans. R, Soc. Lond. A 307, 1982;

6. [Electronic document], access mode: http://www.otec.ws, [reading: 03-04-2013];

7. [Electronic document], access mode: http://www.buch-dersynergie.de/c_neu_html/c_06_10_wasser_temperaturgradient. htm [reading: 03-04-2013];

8. [Electronic document], access mode: http://www.seasolarpower. com, [reading: 03-04-2013];

9. Etemadi A., Emdadi A., Afshar O. A., Emami Y. Electricity Generation by the Ocean Thermal Energy, Energy Procedia 12, 2011;

10.Hung T.C., Wang S.K., Kuo C.H., Pei B.S., Tsai K.F. A study of organic working fluids on system efficiency of an ORC using low-grade energy sources, Energy 35, 2010;

11.Kim N.J., Ng K.CH., Chun W. Using the condenser effluent from a nuclear power plant for Ocean Thermal Energy Conversion (OTEC), International Communications in Heat and Mass Transfer 36, 2009;

12.Kosowski K. Selecting favourable values of basic design parameters for thermal turbines. Generalised method of turbine stage design (in Polish), Scientific reports of the Gdansk University of Technology, Shipbuilding, no LXII, Gdansk, 1995;

13.Lewandowski W. Project of renewable energy sources (in Polish), WTN, Warszawa, 2001.

14.Mikielewicz J., Piwowarski M., Kosowski K. Design analysis of turbines for co-generating micro-power plant working in accordance with organic Rankine's cycle, Polish Maritime Research, S1, ISSN 1233-2585, 2009;

15.Pelc R., Fujita R. M. Renewable energy from the ocean, Marine Policy 26, 2002;

16.omputer code Engineering Equation Solver, Version 9.218, 2012 ;

17.Computer code REFPROP Reference Fluid Thermodynamic and Transport Properties, Version 8, 2007;

18.Rajagopalan K., Nihous G.C. Estimates of global Ocean Thermal Energy Conversion (OTEC) resources using an ocean general circulation model, Renewable Energy 50, 2013;

19.Semmari H., Stitou D., Mauran S. A novel Carnot-based cycle for ocean thermal energy conversion, Energy 43, 2012;

20.Vega L.A. First Generation 50 MW OTEC Plantship for the Production of Electricity and Desalinated, OTC 20957, 
Offshore Technology Conference, Houston, Texas, USA, 3-6 May 2010;

21.Wu Ch., Avery W. H. Renewable Energy From the Ocean: A Guide to OTEC, Oxford University Press, ISBN 0195071999 , 1994;

22. Yamada N., Hoshi A., Ikegami Y. Thermal Efficiency Enhancement of Ocean Thermal Energy Conversion (OTEC) Using Solar Thermal Energy, AIAA 2006-4130, 4th International Energy Conversion Engineering Conference and Exhibit (IECEC), San Diego, California, 26 - 29 June 2006.

\section{CONTACT WITH THE AUTHOR}

Marian Piwowarski, Ph.D. Faculty of Ocean Engineering and Ship Technology

Gdansk University of Technology Narutowicza 11/12

80-233 Gdansk, POLAND

e-mail: piwom@pg.gda.pl 